\title{
IMPACTOS DO CONSUMISMO NO DESENVOLVIMENTO INFANTIL
}

\section{THE IMPACTS OF CONSUMERISM ON CHILD DEVELOPMENT}

\section{IMPACTOS DEL CONSUMISMO EN EL DESARROLLO INFANTIL}

\author{
Aline Cazuza dos Santos \\ Graduação em Psicologia - Faculdades Integradas de Jaú \\ e-mail: alinecazuza@gmail.com \\ Aline Fernanda Tebaldi de Oliveira \\ Graduação em Psicologia - Faculdades Integradas de Jaú \\ e-mail: aline.f.tebaldi@gmail.com \\ Ana Vera Niquerito Bossa \\ Graduação em Psicologia - USC/Bauru \\ Doutora em Ciências da Reabilitação - HRAC/USP \\ Docente das Faculdades Integradas de Jaú \\ e-mail: anavera.n@gmail.com
}

\begin{abstract}
RESUMO
A sociedade contemporânea é caracterizada por suas relações de produção e de consumo, influenciando os comportamentos, a formação de valores e da própria identidade do indivíduo. Nessa sociedade as relações entre adultos e crianças sofreram transformações e o mundo infantil passou a ser visto como um consumidor em potencial. Entretanto, é na infância que ocorre o desenvolvimento biopsicossocial e a formação da personalidade, período em que estas são mais vulneráveis a moldar o seu comportamento com base no que é apresentado pela publicidade e pelo consumismo. Assim, o artigo visa identificar as principais consequências do consumismo no desenvolvimento infantil; analisar os hábitos de consumo durante a infância e descrever os fatores, relacionados ao consumo que influenciam o desenvolvimento infantil, através de uma pesquisa bibliográfica, que teve como critério a utilização de trabalhos publicados nos anos de 2010 a 2017 utilizando-se da base de dados eletrônicos, artigos, e livros de língua portuguesa. A pesquisa demonstrou que as crianças têm apresentado hábitos consumistas que refletem no seu desenvolvimento físico e cognitivo, tanto em aspectos considerados positivos quanto negativos. As frustrações dos desejos criados pela mídia que podem ocasionar na criança problemas relacionados à sua satisfação pessoal e autovalorização.
\end{abstract}

Palavras-chave: Consumismo; Desenvolvimento; Infância.

\section{ABSTRACT}

Contemporary society is characterized by the relation between production and consumption, influencing behavior, value formation and the individual's identity itself. In this society, the relationship between adults and children has been transformed, and children have come to be seen as potential consumers. However, it is during childhood that biopsychosocial development and personality formation occur, a time in which they are more vulnerable to altering their behavior based on their interactions with advertising and consumerism. Thus, this article aims to identify the main consequences of consumerism on child development; to analyze 
consumption habits during childhood and to describe the factors related to consumption that influence the development of children, through a bibliographical research that has as its criterion the use of works published between the years of 2010 and 2017, using digital databases, articles, and books in the Portuguese language.. The research demonstrated that children have demonstrated consumerist habits that are reflected in their physical and cognitive development, encompassing both positive and negative aspects.

Keywords: Consumerism; Development; Childhood.

\section{RESUMEN}

La sociedad contemporánea se caracteriza por sus relaciones de producción y consumo, que influyen en el comportamiento, en la formación de valores e, incluso, en la formación de la identidad del individuo. En esta sociedad, las relaciones entre adultos y niños han sufrido transformaciones y el mundo infantil pasó a ser visto como un potencial grupo de consumidores. Sin embargo, el desarrollo biopsicosocial y la formación de la personalidad ocurren en la infancia, período en el cual los niños son más vulnerables a moldear su comportamiento en base al consumismo y a lo que se presenta en la publicidad. Así, este artículo pretende identificar las principales consecuencias del consumismo en el desarrollo infantil, analizar los hábitos de consumo durante la infancia y describir los factores relacionados con el consumo que influyen en el desarrollo infantil, a través de una investigación bibliográfica donde se tomaron, de una base de datos electrónica, de artículos y de libros de lengua portuguesa, trabajos publicados entre los años 2010 y 2017. La investigación demostró que los niños presentan hábitos consumistas que se ven reflejados en su desarrollo físico y cognitivo, tanto en aspectos positivos como negativos.

Palabras clave: consumismo, desarrollo, infancia.

\section{INTRODUÇÃO}

$\mathrm{Na}$ sociedade contemporânea, as representações da infância são diversas e se diferenciam a partir do espaço e da classe social. Nas questões comerciais, prevalece uma visão ambígua sobre a criança: por um lado as crianças são vistas como ingênuas e desprotegidas, sujeitas as influências das propagandas, e por outro, vistas como consumidoras donas de desejos e vontades próprias (SILVEIRA NETTO; BREI; FLORES-PEREIRA, 2010).

As relações de produção e de consumo têm caracterizado a sociedade contemporânea, influenciando as interações sociais e a própria formação do pensamento humano. As relações estabelecidas entre adultos e crianças sofreram transformações e houve a descoberta de um mundo infantil consumidor. Neste contexto, a mídia conquista todas as faixas etárias, mas principalmente as crianças e adolescentes, pois desde os primeiros anos de vida, estão carregados dessas contingências, e ficam um longo período em contato com artigos de publicidade, seja na TV ou internet, que instigam o consumo, construindo desde muito cedo valores saturados pelo consumo exacerbado (OLIVEIRA; PASCHOAL, 2015).

16

RELEDUC | ISE | v. 2 | n. 1 | fev. 2019 
De acordo com Olmos et al. (2016) quanto mais intenso for a quantidade e variedade de estímulos mercadológicos, mais aumentará a adesão em massa e a necessidade do consumo, pois a mídia tem um papel central em pressionar hábitos de compra. Partindo desse princípio, a comunicação mercadológica, que dita o consumo em massa por entrelinhas, estabelece padrões culturais e comportamentais. Essa relação de consumo beneficia o sistema econômico e alimenta o capitalismo vigente (OLIVEIRA; PASCHOAL, 2015).

O processo de comprar, usar e descartar das relações de consumo, tem se estendido às relações humanas. Os vínculos interpessoais passam a não ser duradouros, assim como a relação entre homem e objeto (SCHUCHOVSKI; PONCIO; SANTOS, 2012). Este processo perpassa todo o ciclo de vida do indivíduo, contudo é na infância que se inicia a formação de diferentes estruturas, tais como emocional, psicológica, biológica e da personalidade, as quais têm influência direta sobre o comportamento consumidor e na construção dos valores sociais (SANTOS; GROSSI, 2007).

Verifica-se então, que as influências de mercado não compõem apenas o universo externo da vida das crianças e jovens, mas participam da formação das representações mentais e emocionais para as exigências de perfeição e adequação, pois é preciso pertencer a um grupo. $\mathrm{Na}$ busca por um ideal inalcançável - manifestos pelo corpo perfeito, capacidades ilimitadas, acesso aos bens de consumo - sentimento de vazio, inadequação e vergonha, integram o mundo mental subjetivo, repercutindo nos laços afetivos que estabelece consigo mesmo, e com outros objetos de amor (OLMOS et al., 2016).

Considerando que a criança, por estar em uma fase singular de seu desenvolvimento, é mais vulnerável aos efeitos prejudiciais do consumismo, sendo de extrema importância que os profissionais que trabalham com o universo infantil, voltem o seu olhar sobre a infância e a ações de mercado relacionadas ao público infantil. Justifica-se a importância deste trabalho devido à sua relevância social, abordando a inserção precoce das crianças no mercado consumidor e relacionando aos aspectos do desenvolvimento cognitivo, físico e social infantil. Presumindo que as influências negativas do consumismo podem desfavorecer o desenvolvimento saudável da criança.

Nesse contexto, o presente estudo teve como objetivo geral identificar as principais consequências do consumismo no desenvolvimento infantil, e como objetivos específicos analisar os hábitos de consumo durante a infância, além de descrever os fatores relacionados ao consumo que influenciam o desenvolvimento infantil. 


\section{O PROCESSO DE FORMAÇÃO DOS HÁBITOS DE CONSUMO E A INSERÇÃO DA CRIANÇA NO MERCADO CONSUMIDOR}

A sociedade de consumo teve seu início com a Revolução Industrial, na Inglaterra, no final do século XVIII. O Estado, com a intenção de viabilizar a expansão industrial, buscou na burguesia o capital e o apoio necessário. A partir de 1929, com o aumento dos preços, os países periféricos desenvolveram uma política voltada à industrialização, ocorreu uma expansão de pequenas indústrias nacionais voltadas à produção de bens essenciais à sobrevivência da classe trabalhadora, tendo como consequência o acúmulo do capital interno e a melhoria da qualidade de vida da população. Nas décadas de 1950 e 1960 passa a haver uma imitação dos países periféricos aos países centrais em relação aos modelos de consumo voltados para produtos de luxo (SANTOS; GROSSI, 2007).

O consumismo é o reflexo da transformação do trabalho artesanal em labor em decorrência da Revolução Industrial. As melhorias de condições de vida dos operários e a agilidade de produção de novos bens transformaram o ato de fabricar e comprar. A utilidade deixou de ser um fim em si, e passou a servir como um meio de alcançar a felicidade (CONTE et al., 2007).

O consumo frequentemente deixa de estar ligado a uma necessidade e se associa a uma emoção. Quando associado ao prazer, o consumo gera uma sensação de insatisfação e os apelos da mídia contribuem para isso. A mídia influencia até mesmo as escolhas de vida, o conceito de felicidade e a autovalorização (SANTOS; GROSSI, 2007). No que se refere à mídia, esta pode ser compreendida como qualquer dispositivo, sejam revistas, computadores, televisão, livros, etc., capaz de se relacionar aos processos de construção de valores, ideias e comportamentos sociais. Isto é, a mídia atua como um elemento cultural de aprendizagem informal, pois dissemina conteúdos que podem produzir um infinito número de impactos no comportamento humano e principalmente infantil (CAETANO, 2016).

O desejo de consumir cria ansiedades, limita a capacidade de reflexão e leva a uma procura por algo capaz de satisfazer essa necessidade. É através desse processo que a mídia se utiliza da publicidade para apresentar coisas novas para que as pessoas consumam e se tornem cada vez mais dependentes da lógica capitalista (BICK et al., 2013).Para Moura, Viana e Loyola (2013), o consumismo produz uma busca por uma satisfação que nunca se concretiza, levando a decepção e a tristeza e produzindo sujeitos insaciáveis em sua demanda de consumo. 
O que move a sociedade de consumo é a frustração dos desejos. Se o consumidor se sentir satisfeito, deixará de consumir, fato que impediria o desenvolvimento dessa sociedade. A satisfação é momentânea e assim deve continuar, pois o que envolve e atrai os consumidores não são os objetos em si, e sim a busca pela satisfação de seus desejos. Dessa forma, os produtos não são criados para serem eternos e sim para serem descartados e substituídos por outros que satisfaçam melhor os desejos pessoais (SCHUCHOVSKI; PONCIO; SANTOS, 2012).

O consumismo surge como um meio de construção de identidades, onde quanto mais os objetos adquirem poder, mais o interior está vazio e exteriorizado. Os indivíduos se reconhecem e se sentem bem quando possuem objetos e marcas que fazem com que eles consigam se ver e se identificar, como se estivessem reduzidos às embalagens (CONTE et al., 2007).

Para Schuchovski, Poncio e Santos (2012) na sociedade de consumo o processo de transformação de pessoas em objetos pode ser evidenciado pelo modo como o próprio corpo é tratado pela publicidade, que explora a exibição corporal e define o que é belo e ideal. O modelo ideal de corpo passa a ser algo a ser consumido, levando a medicina a atender essas demandas de um corpo socialmente aceito. Assim, o modo como a sociedade vê a si mesmo e aos outros passa a ser pautada nas relações objetais, passíveis do consumo e descartáveis.

No que se refere à inserção da criança no mercado de consumo, Bick et al. (2013) apontam as diferentes estratégias que são utilizadas pelo mercado para atingir as crianças. Sendo elas: a imitação, onde a criança reproduz o que vê aceitando ideias prontas do que está sendo apresentado; a sugestão, onde ocorre a insinuação de algo que é tido como ideal; a persuasão, que utiliza a sensibilidade da criança por diferentes motivações afetivas e, a pressão moral, que faz com que a criança se sinta culpada por não realizar o que é imposto pela mídia. Em relação à pressão moral, as autoras exemplificam com a criança que se sente culpada por não presentear a mãe em datas comerciais com o presente que foi apresentado pela mídia. Assim, utilizando-se dessas estratégias o mercado com apelo consumista desperta na criança sentimentos e desejos que não são controlados conscientemente.

$\mathrm{Na}$ cultura do consumismo, as propagandas direcionadas ao público infantil têm métodos para chamar a atenção das crianças, usam uma linguagem que elas gostem e utilizam muitas crianças na propaganda. Toda essa identificação também é vendida pela publicidade ao fazerem com que as pessoas se sintam bem e sentirem que possuem uma importância para essa sociedade, assim como é transmitido nas mensagens publicitárias (SCHUCHOVSKI; PONCIO; SANTOS, 2012). 
No sentido de proteger as crianças do direcionamento abusivo da publicidade a esse público infantil, em abril de 2014, foi publicada a resolução 163/2014 do Conselho Nacional do Direito da Criança e do Adolescente (CONANDA), que proíbe qualquer tipo de direcionamento à criança que estimule o consumo (CONANDA, 2014).

Apesar da propaganda direcionada a criança ter sido considerada abusiva e ilegal no Brasil desde 2014, o mercado continua a fazer anúncios direcionados ao público infantil em diferentes mídias. Embora exista publicidade benéfica, as mensagens publicitárias são na maioria persuasivas e se aproveitam da vulnerabilidade da população em geral, sendo uma arma das indústrias e que tende a manipular a mente dos consumidores (CRAVEIRO, 2016). No entanto, a publicidade não pode ser considerada como a única causa do consumismo, pois a cultura do consumidor também é um fator que determina as prioridades publicitárias. (SCHUCHOVSKI; PONCIO; SANTOS, 2012).

Embora existam órgãos de regulamentação e instituições que visam preservar a integridade infantil e se preocupam em garantir os direitos das crianças, é papel dos pais, principalmente, prevenir as crianças da exposição excessiva às influências nocivas da propaganda. A utilização da televisão e da internet deve ter a supervisão dos pais, que devem também discutir com seus filhos sobre os significados contidos nas estratégias de marketing. Quando não existe a orientação por parte dos pais, podem haver consequências negativas que colaboram para a formação do consumismo infantil (FREITAS; APOLÔNIO, 2015).

Faz-se necessário ter alguns cuidados ao se desenvolver produtos e mensagens publicitárias para as crianças, atentando-se ao modo com que essas mensagens serão interpretadas. A intenção não é proibir ou isolar essa faixa etária dos fatos, mas é importante acompanha-los e orientá-los no que se refere às mensagens midiáticas e supervisionar os programas assistidos. A televisão faz parte da grande maioria dos lares e constitui uma realidade, sendo necessário aprender a conviver de modo a reduzir os possíveis efeitos nocivos ocasionados por esta. Desta forma, quando houver cenas de violência, uso de drogas, ou banalização da sexualidade é fundamental expor a real problemática ao público infantil, auxiliando na compreensão do que está sendo veiculado (SANTOS, 2010).

\section{O DESENVOLVIMENTO INFANTIL E O CONSUMISMO NA INFÂNCIA}

Em decorrência dos avanços tecnológicos, percebeu-se alterações nas relações sociais, principalmente relacionadas às primeiras fases do desenvolvimento humano, fazendo com que 
os impactos na compreensão da subjetividade contemporânea tenham se tornado um assunto de investigação acadêmica (CORRER; FAIDIGA, 2017).

Piaget apresenta quatro estágios do desenvolvimento cognitivo. O estágio sensório motor, compreende ao período dos 0 aos 2 anos e se baseia nos sentidos e habilidades motoras, nesse estágio é desenvolvido o emprego das representações mentais. Na fase do pensamento pré-operatório, dos 2 aos 6 anos, ocorre a aprendizagem e utilização dos símbolos para representar aspectos sobre o mundo, mas a criança se relaciona com eles somente a partir de sua própria perspectiva. No estágio do pensamento operatório-concreto, 7 aos 11 anos, a criança entende e aplica operações lógicas as suas experiências, desde que sejam centradas no aqui e agora. No último estágio, denominado pensamento operatório-formal, após os 12 anos, o adolescente ou adulto já é capaz de pensar abstratamente, levantar situações hipotéticas e raciocinar dedutivamente sobre o possível (VELOSO, 2008).

Utilizando-se das características do desenvolvimento cognitivo das crianças, as empresas desenvolvem suas estratégias de marketing e segmentação de mercado para atingir o público infantil. Aplicando a teoria de Piaget ao marketing, as empresas seguem as seguintes orientações: para os bebês desenvolvem brinquedos que estimulam o desenvolvimento sensorial e que propiciem a interação entre a criança e os pais; para as crianças pequenas desenvolvem produtos que propiciem atividades de consumo de energia como brinquedos, filmes e jogos; para as crianças que se encontram no período operatório-concreto, as empresas fazem uso de produtos que teoricamente auxiliam as crianças a se sentirem aceitas em um grupo e; para os adolescentes deverá fornecer contestação e autoestima, assim marcas que se posicionam contra o poder estabelecido terão a preferência dos jovens e os itens que forneçam aparência, autoestima, poder e aceitação social são tidos como mais importantes (FERREIRA, 2015).

Em tempos de convergência midiática, as empresas não utilizam somente a propaganda televisiva. Na busca de atingir o público infantil, as empresas fazem uso da televisão, de canais na internet, comunidades, redes sociais e mundos interativos criados pelas próprias marcas (LEÃO; MARTINS, 2011).

No que se refere a propagandas e programas televisivos, ao se assistir televisão, a capacidade de entender informações midiáticas são ativadas. Capacidades como processamento de conteúdo, temporalidade e a forma da mensagem (técnicas de reprodução de vídeo, zoom, cortes, efeitos sonoros, etc.) são articuladas, sendo fundamentais para a compreensão do conteúdo do programa. De acordo com o desenvolvimento da criança, há uma compreensão do 
conteúdo transmitido pela mídia. Assim, crianças de 2 anos, apresentam limitações ao assistir televisão, visto que suas capacidades estão voltadas para o real e interações sensoriais. Já crianças de até 7 anos, possuem pouca capacidade de descrever de forma cronológica do início ao fim de uma história e os motivos que repercutiu nos fatos, isto é, as motivações da ação, geralmente elas contam apenas as ações dos personagens. Crianças de 8 a 10 anos, possuem melhor capacidade de interpretação temporal, técnicas de zoom, efeitos sonoros e cortes, adquirindo a habilidade em compreender a motivação dos personagens e sua ação, inferindo julgamento se a cena é positiva ou negativa no quesito moral (SHAFFER; KIPP, 2012).

Craveiro (2016) em sua pesquisa mapeou três tipos de publicidade presentes em sites, jogos e canais infantis, que dialogam com as crianças no ambiente on-line. Segundo a autora há a publicidade que se apresenta separada do conteúdo do site, como classificados, banners, entre outros, e que dependendo da idade da criança permite que haja uma diferenciação entre a publicidade e o conteúdo do site. O segundo tipo identificado é a propaganda considerada intrusiva por surgir por cima ou entre o conteúdo acessado, atrapalhando a interação do usuário e tornando a separação entre conteúdo e publicidade mais difusa. O terceiro tipo é a publicidade integrada ao conteúdo do site, que utiliza estratégias publicitárias, tais como patrocínios, jogos de determinada marca e youtubers mirins, mesclando a publicidade ao conteúdo do site e tentando promover uma experiência lúdica entre o usuário e a marca.

Além da propaganda propriamente dita, outras estratégias publicitárias também são utilizadas para atingir o consumidor infantil. No mercado de alimentos, por exemplo, junto as guloseimas são oferecidos desenhos divertidos e coloridos, as embalagens apresentam jogos interativos e alguns produtos são acompanhados de brinquedos (OLIVEIRA; REAL, 2011).

As crianças são capazes de reconhecer marcas utilizadas em suas casas mesmo quando os produtos não são diretamente utilizados por elas. A memorização da criança é mais gráfica do que verbal, assim associando a marca e o nome a um personagem ou símbolo, facilitam a memorização. A partir dos 4 anos as crianças já são capazes de associar o logotipo ao produto, através de suas cores e formas, mesmo que não haja compreensão do significado da marca. Aos 6 anos com o processo de alfabetização já se tornam capazes de compreender a marca independente de personagens, dando início a compreensão da linguagem simbólica, porém os personagens continuam despertando o interesse até por volta dos 10 anos, quando então são substituídos por ídolos como artistas e atletas. Assim, ao utilizarem personagens conhecidos pelo público infantil em propagandas e embalagens, as empresas fornecem uma dimensão lúdica e afetiva que geram numerosas vantagens para as mesmas, uma vez que possibilita a 
identificação e influencia a preferência pelos produtos e a fidelização à marca (MOREIRA et al., 2013).

A opinião das crianças nas decisões de compra vem sendo mais ouvida pelos adultos. Essa situação pode ser atribuída ao fato de que os indivíduos estão envolvidos em um ciclo onde é necessário trabalhar para comprar o que quiser, satisfazer os seus desejos e assim se tornarem mais felizes. Esse ciclo reforça a transformação das pessoas em objetos e fragiliza os vínculos pessoais e familiares. É cada vez mais comum os pais terem menos tempo para os filhos e buscarem suprir essa falta com presentes e dinheiro (SCHUCHOVSKI; PONCIO; SANTOS, 2012).

O consumo faz com que a criança se sinta participante da sociedade que está inserida. Para ser igual aos seus colegas a criança precisa estar submetida aos moldes estabelecidos pelo marketing e pela publicidade que estão sempre estabelecendo novos estilos de vida em conformidade com as regras de consumo (LEÃO; MARTINS, 2011).

De acordo com Freitas e Apolônio (2015) as crianças têm grupos de referência, sendo por meio destes que ocorre a aprendizagem do ato de compra, são eles a família, os amigos e as instituições sociais. Na família, os pais são os principais responsáveis pela formação dos valores nos filhos, seja em relação à postura, estilo de vida ou consumo. A interação com os amigos relaciona-se com a busca por aprovação social, e a comparação entre as posses é um fenômeno real, que incentiva o consumo. Já as instituições sociais, são representadas pela mídia e seus diversos meios de comunicação.

Flores (2011) aponta que as relações sociais se reestruturam com o decorrer do tempo, e o próprio modelo familiar possui novos papéis de mulheres, homens e das próprias crianças. São comuns famílias onde os pais são separados ou com mulheres possuindo o controle financeiro familiar. Juntamente a isso, o mundo torna-se acelerado devido ao fenômeno da globalização, caracterizado pela diversidade de informação e conhecimento que se espalha com o capitalismo informacional.

As experiências cotidianas das crianças são cada vez mais preenchidas por histórias, imagens e objetos produzidos pelas empresas midiáticas com atuação no mundo todo, oferecendo as crianças valores, padrões e modelos de comportamento (CRAVEIRO, 2016).

Para Moreira et al. (2013) os brinquedos estão sendo adequados e modificados para atender aos desejos infantis. Bonecas e carrinhos ainda fazem parte da infância, porém a cada dia ganham mais movimentos e tecnologias, assim como os jogos que antes simbolizavam dinheiro com papel agora utilizam máquinas muito semelhantes às de cartão de crédito. Dessa

$$
\text { RELEDUC | ISE | v. } 23 \text { | n. } 1 \text { | fev. } 2019
$$


forma, o modo de brincar da criança acaba sendo influenciado pelas transformações ocasionadas pela sociedade de consumo.

O brinquedo constitui uma forma de desenvolvimento de habilidades e de relações da criança, mas sua função tem sido modificada pela sociedade de consumo. O excesso de ofertas atribui uma descartabilidade aos produtos logo após serem adquiridos, criando o desejo por novas aquisições. Essa relação com o brinquedo caracteriza um ato compulsivo que tem reflexos na estrutura da personalidade das crianças. A descartabilidade com que os objetos são tratados refletirá nos laços afetivos tornando-os vulneráveis. As relações interpessoais tendem a ser caracterizadas pela superficialidade, consumismo e descartabilidade de acordo com a necessidade (SANTOS; GROSSI, 2007).

Outros fatores contribuem para modificar a maneira de brincar das crianças, como a violência nas ruas, somada a ausência dos pais devido ao trabalho e as mudanças nas configurações familiares. As brincadeiras infantis deixaram de ocupar as ruas e parques, e as crianças passam grande parte do dia dentro de casa, fazendo com que elas desenvolvessem novas formas de brincar, imaginar e construir sua realidade infantil. Nesse panorama, a mídia e os novos equipamentos tecnológicos exercem um fascínio sobre o público infantil, ocupam grande parte da rotina das crianças e desempenham uma importante função na transmissão de valores socialmente aceitos e tidos como importantes para as famílias, influenciando indiretamente as crianças a se comportarem de acordo com esses valores (BICK et al., 2013).

\section{AS INFLUÊNCIAS DO CONSUMISMO NO DESENVOLVIMENTO INFANTIL}

A infância é uma fase peculiar do desenvolvimento, as emoções, a personalidade e corpo ainda estão em formação. Portanto, a questão do consumo na infância ultrapassa a questão comportamental e interfere na sua formação, influenciando na saúde, na educação e nos valores da sociedade do futuro (SANTOS; GROSSI, 2007).

A publicidade, os meios de informação e a tecnologia contribuem para um encurtamento da infância, onde os brinquedos acabam sendo deixados de lado e roupas, cosméticos, aparelhos e jogos eletrônicos ganham a preferência dos pequenos consumidores. Para Craveiro e Rios (2013), os jogos online e a internet se tornaram o meio pelo qual foram reestruturadas as brincadeiras infantis, proporcionando novas maneiras de construir e participar da cultura lúdica infantil. No entanto, esses meios além de proporcionar em crianças novas emoções enquanto jogam, é também um espaço de transmissão de conteúdo comercial de marcas e empresas, que

$$
\text { RELEDUC | ISE | v. } 24 \text { | n. } 1 \text { | fev. } 2019
$$


não enxergam as crianças como simples usuárias dos jogos, mas sim como consumidoras no ambiente virtual.

$\mathrm{Na}$ cultura do consumo, as crianças são cada vez mais expostas aos equipamentos tecnológicos e as programações televisivas. Para Santos e Grossi (2007) essa exposição, além do sedentarismo, influencia na formação educacional dos jovens. Embora a programação televisiva apresente alguns programas criativos e didáticos voltados ao público infantil, a mesma também é responsável pela propagação de conteúdos negativos como violência e incentivo ao consumo. Assim, a televisão influencia tanto na saúde física quanto emocional, na educação, na criatividade e nos valores das crianças que ainda não possuem a capacidade de realizar o julgamento adequado das propagandas e informações as quais ficam expostas.

A exposição às informações vinculadas pela mídia televisiva pode ocasionar alguns efeitos indesejáveis. A violência apresentada pela televisão para o público infantil, desperta preocupações de pais e professores, sobre possíveis consequências no desenvolvimento da criança. Através de estudos sobre o tema, verificou-se que os programas mais violentos, são destinados ao público infantil em forma de desenho animado, sendo os protagonistas dos atos violentos, os heróis, que são referência para os pequenos (SHAFFER; KIPP, 2012).

Com relação aos impactos da televisão nas crianças, percebeu-se que aquelas que possuem mais contato com esse tipo de mídia, possuem declínio no desenvolvimento da criatividade e no envolvimento com a sociedade, assim como, apresentam um aumento considerável da agressividade e da estereotipização dos gêneros. Entretanto, tais informações possuem outra perspectiva, visto que a criança que permanece muito tempo assistindo televisão, não participa de outras atividades de lazer, culturais, educativas e com pares. Desta forma, se o ato de assistir televisão não for demasiado, o público infantil não apresentará prejuízos em funções acadêmicas, cognitivas, e sociais (SHAFFER; KIPP, 2012).

Através da excitação ocasionada pela exposição à televisão, o comportamento das crianças pode ser afetado. A intensidade de qualquer emoção poderá ser afetada por essa exposição, inibindo ou encorajando certos comportamentos como, por exemplo, a violência e uso de álcool (SANTOS; GROSSI, 2007). A televisão possui impactos nos comportamentos, colaborando para o aumento da violência entre crianças e jovens, para a obesidade infantil e como estímulo ao desenvolvimento da sexualidade precoce (MOURA; GARCIA, 2008).

A exposição prolongada à televisão pode ocasionar prejuízos à saúde das crianças. O índice de obesidade vem crescendo em todas as faixas etárias, especialmente entre crianças e jovens. A obesidade é uma ameaça à saúde física, pois contribui para doenças cardíacas,

$$
\text { RELEDUC | ISE | v. } 2 \text { | n. } 1 \text { | fev. } 2019
$$


hipertensão e diabetes. O hábito de assistir televisão é considerado uma prática sedentária, visto que quando uma criança está em brincadeiras mais ativas ou até mesmo realizando atividades domésticas, tem a possibilidade de maior gasto calórico. Desta forma, no tempo em que assiste à televisão, as crianças deixam de praticar atividades físicas, bem como são estimuladas pela programação aos maus hábitos alimentares, induzindo a ingestão de alimentos calóricos, com pouco teor nutricional, rico em sódio, açúcares e gordura (SHAFFER; KIPP, 2012).

Para Schuchovski, Poncio e Santos (2012) são inúmeros os anúncios publicitários que incentivam o consumo exagerado de alimentos pobre em nutrientes como meio para obter algum brinde, geralmente brinquedos. O produto anunciado deve ser consumido como meio de satisfação do desejo criado pela própria publicidade.

O uso de drogas e a criminalidade podem ser vistos como efeitos de fatores econômicos, políticos e subjetivos ligados aos ideais sociais de consumo. No entanto, tais comportamentos aparecem publicamente como ameaças legitimadas por ações de controle social, mas que aparecem socialmente como se não houvesse razões para sua produção. A propaganda incita o desejo por objetos criados para nossa satisfação, mas esse desejo não é eliminado com o consumo, e sim transferido para outros objetos. Essa instrumentalização de desejos para objetos pode ser realizada também para o objeto drogas, fazendo com que esta se torne um modelo de consumo e de relações sociais. As toxicomanias, entendidas como a dependência não só de drogas, mas também de sexo, jogos, compras, entre outras, são a expressão de uma saída pela fascinação em relação aos objetos de consumo. A droga, para o toxicomaníaco, seria a escolha de um objeto adequado, acessível, que pode ser também compreendida como um atalho para a felicidade (CONTE et al., 2007).

Os grupos sociais funcionam como um espelho, o que é consumido depende da imagem que o indivíduo deseja passar aos outros componentes do grupo. O grupo social passa a ser uma influência para o consumo. Sendo que o comportamento consumista passa a ser evidenciado também nas redes sociais que não se restringem ao público adulto, mas também atingem jovens e crianças (LEÃO; MARTINS, 2011).

Para Conte et al. (2007) tanto o consumo em geral quanto o consumo de drogas cumpririam a mesma função de anestesiar o mal-estar social, criar uma ilusão de felicidade e de pertencimento e mobilidade social. Para muitos jovens em vulnerabilidade social, o tráfico de drogas representa uma atividade profissional, ainda que ilícita, é uma maneira de tentar responder com as condições que tem, às exigências básicas e de consumo de suas famílias. A escola do crime ocorre através dos pais e outros familiares, que atuam na transmissão de formas

$$
\text { RELEDUC | ISE | v. } 26 \text { | n. } 1 \text { | fev. } 2019
$$


de enfrentar a realidade e que com a naturalização do crime, muitas crianças crescem fascinadas por armas e drogas.

Além dessas consequências, a erotização precoce, também pode ser apontada com um efeito do consumismo no desenvolvimento infantil. Para De Freitas e Apolônio (2015) os padrões de beleza aparecem na propaganda e o apelo à utilização de tecnologias para o embelezamento do corpo é nítido na formação da identidade infantil feminina. É cada vez mais comum as meninas se preocuparem com seu corpo e sua beleza, recorrendo a serviços oferecidos em salões de beleza e a tratamentos estéticos, ocorrendo uma adultização dessas meninas.

Segundo Santos (2010) a estimulação da sexualidade de maneira antecipada, também pode acarretar problemas psicológicos a médio e longo prazo no público infantil, tais como: antecipação da menstruação, gravidez precoce, doenças sexualmente transmissíveis, baixo desempenho escolar, distúrbios alimentares, depressão e a banalização da sexualidade, pois o acúmulo de cenas sexuais na cabeça das crianças pode fazer com que se aprenda a enxergar o sexo de forma banalizada, como algo que se deve fazer, pois é praticado por todos, e não como algo com um significado pessoal, ocasionando entre outras graves consequências o aumento da pedofilia no mundo adulto.

Da mesma forma, ao mesmo tempo em que a internet possibilita o acesso e divulgação de novos conhecimentos, proliferam os crimes cibernéticos, dentre eles, a pedofilia. A pedofilia sempre esteve presente na história da humanidade, porém a internet lhe proporcionou maior visibilidade e possibilitou a melhor organização dos grupos de pedófilos. O sexo, a nudez e a pornografia são evidenciados em diferentes mídias as quais as crianças possuem cada vez mais acesso, ao mesmo tempo em que a educação sexual das crianças é silenciada e negligenciada. $\mathrm{Na}$ tentativa de proteger as crianças, os pais fazem uso de softwares que bloqueiam o acesso a determinados conteúdos considerados impróprios ao público infantil. No entanto, as crianças demonstram muita facilidade em lidar com tais ferramentas, desbloqueando os sistemas de proteção. Portanto, as crianças devem ser orientadas e encorajadas a se protegerem na internet em relação às informações que acessam ou repassam (PRESTES; FELIPE, 2015).

Por outro lado, meninas e mulheres que assistem a programas que reforçam os padrões sociais de beleza, tornam-se mais insatisfeitas com a própria aparência, podendo ter implicações reais no autoconceito e na autoestima, sendo mais suscetíveis a transtornos alimentares de risco como anorexia e bulimia na adolescência (SHAFFER; KIPP, 2012). 
O consumismo na infância também tem seus reflexos nas formas de relacionamento interpessoal das crianças. O bullying, possui aspectos desencadeantes que são reflexos da sociedade de consumo. A transformação do corpo em um objeto de consumo na sociedade atual faz com que as crianças passem a valorizar as características do corpo socialmente perfeito. Nesse contexto, a criança da sociedade de consumo ao olhar e notar que outra criança está em desconformidade com os padrões de beleza, a exclui de seu círculo de amizades e atribui apelidos que menosprezam o corpo que não está dentro do padrão de beleza que é exibido pela TV e pelas revistas. (SCHUCHOVSKI; PONCIO; SANTOS, 2012).

O uso dos equipamentos tecnológicos, por indivíduos cada vez mais jovens, tem se intensificado, acarretando em consequências tanto positivas quanto negativas. $\mathrm{O}$ uso do celular, por exemplo, favorece o desenvolvimento da maturidade através da privacidade e autonomia que fornece aos adolescentes. Além disso, possibilita aos pais maior contato, controle à distância e mais segurança no processo de separação-individuação dos filhos. Entretanto, ao mesmo tempo, pode favorecer alterações no ambiente escolar, seja pela dispersão que provoca aos alunos ou pela possibilidade de bullying (CORRER; FAIDIGA, 2017).

É fundamental ressaltar que o consumo desenfreado também compromete o futuro do planeta. A sociedade caminha para o esgotamento de bens naturais, pois com práticas de compras impensadas e não sustentáveis, o planeta acabará não suprindo à grande demanda de matéria prima para satisfazer a ambição da sociedade consumista. Além desse fator, há também o fortalecimento e o aumento da produção de lixo, ocasionada pelo excesso consumo. A regra é simples, quanto mais consumo, mais lixo é gerado (SANTOS, 2010).

A sociedade do consumo é também uma sociedade que tem que encontrar soluções para os problemas ecológicos por ela criados. No entanto, para a superação da crise ambiental é necessário à superação dos padrões de consumo vigentes. Para que isso aconteça é necessário disseminar práticas educacionais que atribuam mais importância a outras atividades do que ao fato de consumir e que possibilite a capacidade de distinguir entre necessidades reais e as que são impostas, o que implica em mudança de comportamentos, relações e formas de pensar. Uma educação para o consumo requer a aprendizagem de novos hábitos, como o controle da impulsividade para que assim se possa evitar desperdícios (ZANIRATO; ROTONDARO, 2016).

No entanto, não se pode atribuir apenas aos apelos midiáticos do consumismo as influências negativas no desenvolvimento infantil. Bick et al. (2013) consideram que a programação televisa, por exemplo, é apenas um elemento de socialização e formação da RELEDUC | ISE | v. 2 | n. 1 | fev. 2019 
personalidade. As crianças que vivem em um ambiente onde o relacionamento entre as pessoas se dá com base em discussões e brigas, sofrerá muito mais com os efeitos nocivos de uma programação que também apresente esses comportamentos agressivos do que em relação à criança que assiste a mesma programação, mas que vivencia um relacionamento familiar afetuoso e com o diálogo para resolver conflitos.

Cabe ressaltar o papel positivo que a mídia também exerce sobre o desenvolvimento infantil. Os programas televisivos, que apresentam os dramas cotidianos da vida das crianças, as ajudam a entender e a desenvolver estratégias para superar essas dificuldades. Assim como, os programas que são planejados com conteúdos educativos e valores positivos para as crianças auxiliam o processo de desenvolvimento infantil, as crianças que assistem a esses programas apresentam comportamentos pró-sociais, habilidades e valores que as auxiliam na vida escolar, familiar e socialmente (BICK et al., 2013).

Na compreensão do consumismo infantil é necessário reconhecer as tendências atuais, por exemplo, a do modelo familiar tradicional, onde os pais separados por possuírem sentimento de culpa devido a sua ausência na criação dos filhos, compensam a sua falta cedendo aos pedidos dos filhos adquirindo os objetos de desejo dos mesmos e assim, contribuindo para a formação de indivíduos cada vez mais consumistas (FREITAS; APOLÔNIO, 2015).

Schuchovski, Poncio e Santos (2012) defendem que o estímulo ao desejo de consumo acaba voltando as crianças contra os seus próprios pais, uma vez que esses são vistos como o que impede a satisfação do desejo e a inserção do filho na sociedade padronizada de consumidores. No entanto, o relacionamento entre pais e filhos, quando um processo colaborativo e com comunicação clara, promove autonomia da criança, descoberta de novas habilidades como de julgamento, se é correto ou não, de oportunidade de escolha, porém com delimitações, e construção de responsabilidades, de acordo com sua capacidade. Por outro lado, os pais são considerados modelos para as crianças, os quais devem ser imitados. Assim, com o aumento dos estímulos midiáticos, há uma frequência cada vez maior de pais e outros adultos que apresentam hábitos consumistas. Consequentemente, a criança imitará exemplos diretos, aprendendo a comprar e consumir mais produtos, associando à necessidade de satisfação de necessidades e desejos (MOURA; VIANNA; LOYOLA, 2013).

Os pais proporcionam às crianças as primeiras experiências de compra, elas são ouvidas na aquisição dos produtos para a família e também recebem mesadas que possibilitam que as mesmas realizem compras com seu próprio dinheiro. Tais atitudes fornecem um espaço para que a criança demonstre sua personalidade, promova a sua independência e estabeleça noções 
econômicas, uma vez que a mesma pode optar por gastar ou investir seu dinheiro para aquisições melhores no futuro (MOREIRA et al., 2013).

Para Vale e Maciel (2016), a escola e a família tem o poder de desconstruir as realidades criadas pelo consumismo através do estabelecimento de limites, mas sem gerar a sensação de castração. Tanto os pais quanto os professores deveriam entender e mensagens publicitárias e, discutir com as crianças utilizando uma linguagem adequada para cada faixa etária.

\section{CONSIDERAÇÕES FINAIS}

Considerando os objetivos estabelecidos neste estudo, foi possível concluir que a cultura do consumismo pode influenciar o desenvolvimento infantil em aspectos considerados negativos. No entanto, o consumo quando realizado de forma consciente apresenta fatores positivos ao desenvolvimento da criança.

Dentre as consequências negativas do consumismo, durante o desenvolvimento infantil, estão a propensão aos transtornos alimentares, comportamentos violentos, criminalidade, uso de álcool e drogas, erotização precoce, facilitação da pedofilia, dificuldades de relacionamentos interpessoais, alterações no ambiente escolar / bullying, comportamentos não sustentáveis e prejuízos nas relações entre pais e filhos.

As consequências positivas relativas ao consumo, estão relacionadas ao desenvolvimento da maturidade e autonomia, fortalecimento do vínculo parental por meio de equipamentos tecnológicos, disseminação do conhecimento e acesso a programas educativos que auxiliam na promoção do desenvolvimento da personalidade e maturidade.

Referente aos hábitos de consumo na infância foi identificado que são originados nos valores transmitidos pelas mídias e na aprendizagem com os pais, amigos e familiares. Os principais hábitos de consumo na infância se referem à aquisição de brinquedos e jogos eletrônicos, alimentos, roupas, cosméticos, aquisição de serviços e tratamentos estéticos e utilização de sites e canais infantis.

Os fatores relacionados ao consumismo e que influenciam o desenvolvimento infantil estão relacionados às possíveis frustrações dos desejos criados pela mídia, que podem ocasionar na criança problemas relacionados à sua satisfação pessoal e autovalorização. O desejo de consumo cria ansiedades, que podem influenciar na capacidade emocional e de reflexão da criança. 
Identificou-se que a mídia e os avanços tecnológicos se constituem como principais fatores relacionados ao consumismo e que influenciam o comportamento infantil. Em razão do seu processo de desenvolvimento, as crianças apresentam uma vulnerabilidade psíquica, sendo muitas vezes incapazes de diferenciar a realidade do conteúdo publicitário. Dessa forma, aceitam como verdades inquestionáveis tudo aquilo que é visto na mídia, moldando seu comportamento e ações sociais com base nos moldes estabelecidos pela publicidade, e em conformidade com as regras do consumismo.

Portanto na cultura consumista são impostos valores, ideias e comportamentos tidos como socialmente adequados. Nessa cultura, consumir é sinônimo de pertença social, faz parte do processo de construção de identidades e influencia o modo de ser. Esses fatores influenciam o modo como à criança se desenvolve e se relaciona em sociedade. Na infância as emoções, a personalidade e o próprio corpo estão em desenvolvimento. Portanto, a absorção dos valores impostos pela cultura do consumo influencia o desenvolvimento não só na questão comportamental, mas também na saúde, na educação e nas relações sociais.

Considera-se que é necessária a realização de mais estudos em relação ao assunto, em busca de repensar as informações pautadas no consumismo que estão sendo repassadas as nossas crianças, levando em consideração que as experiências infantis repercutem ao longo da vida, influenciando nos valores e comportamentos da sociedade do futuro.

\section{REFERÊNCIAS}

BICK, V. T. et al. As influências da mídia no desenvolvimento infantil. Rev. Psicologia em Foco, Frederico Westphalen, v. 5, n. 5, p. 101-115, jul. 2013. Disponível em: $<$ http://www.revistas.fw.uri.br/index.php/psicologiaemfoco/article/view/1105>. Acesso em: 04 mai. 2017.

BREI, V. A.; GARCIA, L. B.; STREHLAU, S. A influência do marketing na erotização precoce infantil feminina. TPA-Teoria e Prática em Administração, João Pessoa, v. 1, n. 1, p. 97116, 2012. Disponível em: < http://periodicos.ufpb.br/index.php/tpa/article/view/11899>. Acesso em: 25 mar. 2017.

CAETANO, M. R. Adultilização na infância: as representações das crianças dos anos iniciais do ensino fundamental. Zero-a-Seis, Florianópolis, v. 18, n. 33, p. 83-107, mar. 2016. ISSN 1980-4512. Disponível

em: <https://periodicos.ufsc.br/index.php/zeroseis/article/view/19804512.2016v18n33p83/31490> . Acesso em: 10 jun. 2017. 
CONSELHO NACIONAL DOS DIREITOS DA CRIANÇA. Resolução no $\mathbf{1 6 3}$, de 13 de março de 2014. Brasília: Secretaria Especial dos Direitos Humanos. Disponível em: <http://dh.sdh.gov.br/download/resolucoes-conanda/res-163.pdf. >. Acesso em 18 abr. 2017.

CONTE, M. et al. Consumismo, uso de drogas e criminalidade: riscos e responsabilidades. Psicol. cienc. prof., Brasília, v. 27, n. 1, p. 94-105, mar. 2007. Disponível em: < http://www.scielo.br/scielo.php?script=sci_arttext\&pid=S141498932007000100008\&lng=en \&nrm=iso> . Acesso em: 09 jul. 2017.

CORRER, R.; FAIDIGA, M. T. B. O uso do celular por adolescentes: impactos nos relacionamentos. Adolesc. Saude, Rio de Janeiro, v. 14, n. 2, p. 24-39, 2017. Disponível em:< http://www.adolescenciaesaude.com/detalhe_artigo.asp?id=647>. Acesso em: 20 jul. 2017

CRAVEIRO, P. S. U. Publicidade e infância: estratégias persuasivas direcionadas para crianças na internet. Culturas Midiáticas, João Pessoa, v. 9, n. 1, p.16-32, 2016. Disponível em: <http://periodicos.ufpb.br/index.php/cm/article/view/29357>. Acesso em: 15 jun. 2017.

CRAVEIRO, P. S.; RIOS, J. R. A publicidade e a cultura do brincar on-line pelo olhar de crianças espanholas e brasileiras. Comunicando, Lisboa, v. 2, n. 2, p. 203-220, 2013. Disponível em:

http://www.revistacomunicando.sopcom.pt/ficheiros/2013122713._apublicidadeeaculturadobr incar.doc.pdf . > Acesso em: 10 mai. 2017.

FERREIRA, A. R. Publicidade infantil: impactos sobre o desenvolvimento da criança. In: CONGRESSO BRASILEIRO DE CIÊNCIAS DA COMUNICAÇÃO-INTERCOM, XXXVIII, Rio de Janeiro, 2015. Anais e Resumos... São Paulo: Intercom- Sociedade Brasileira de Estudos da Comunicação, 2015. Disponível em: <portalintercom.org.br/anais/nacional2015/resumos/R10-1163-1.pdf〉. Acesso em: 30 ago. 2017.

FLORES, A. L. P. et al. Erotização e infância: as duas faces da publicidade. Anagrama, São Paulo, v. 4, n. 3, p. 1-13, fev. 2011. ISSN 1982-1689. Disponível em: <https://www.revistas.usp.br/anagrama/article/view/35511/38230>. Acesso em: 12 ago. 2017

FREITAS, A. A. F. de; APOLÔNIO, L. P. M. Nascidos para comprar: notas sobre o consumismo infantil. Zero-a-Seis, Florianópolis, v. 17, n. 32, p. 210-223, 2015. Disponível em: $<$ https://periodicos.ufsc.br/index.php/zeroseis/article/view/1980-4512.2015n31p210>. Acesso em: 15 jul. 2017.

LEÃO, D. de C. L.; MARTINS, F. M. Cibercultura Infantil: um olhar pelo consumo. In: CONGRESSO DE CIÊNCIAS DA COMUNICAÇÃO NA REGIÃO SUDESTE, XVI, São Paulo, 2011. Anais...São Paulo: Intercom- Sociedade Brasileira de Estudos da Comunicação, 2011.

Disponível

em:

<http://www.intercom.org.br/papers/regionais/sudeste2011/resumos/R2411161.pdf.> Acesso em 23 jun. 2017.

MOREIRA, A. G. et al. Marketing e sua relação com o público infantil. Revista Científica online-Tecnologia, Gestão e Humanismo, Guaratinguetá, v. 2, n. 1, p.67-78, 2013. Disponível em: <http://www.fatecguaratingueta.edu.br/revista/index.php/RCO-TGH/article/view/39.> Acesso em: 23 jun. 2017.

$$
\text { RELEDUC | ISE | v. } 2 \text { | n. } 1 \text { | fev. } 2019
$$


MOURA, L. T.; GARCIA, A. Convivendo no intervalo: relacionamento interpessoal de crianças em comerciais de televisão voltados para o público infantil. Psicologia em Revista, Belo Horizonte, v. 13, n. 1, p. 107-122, nov. 2008. ISSN 1678-9563. Disponível em: <http://periodicos.pucminas.br/index.php/psicologiaemrevista/article/view/263>. Acesso em: 11 mai. 2017.

MOURA, T. B. de; VIANA, F. T.; LOYOLA, V. D. Uma análise de concepções sobre a criança e a inserção da infância no consumismo. Psicol. cienc. prof., Brasília, v. 33, n. 2, p. 474489, 2013 . Disponível em: <http://www.scielo.br/scielo.php?script=sci_arttext\&pid=S14 1498932013000200016\&lng=pt\&nrm=iso>. Acesso em: 04 abr. 2017.

OLIVEIRA, L.; REAL, E. Publicidade, consumo e comportamento infantil. In: CONGRESSO DE CIÊNCIAS DA COMUNICAÇÃO NA REGIÃO NORDESTE, XIII, Maceió, 2011. Anais e Resumos...São Paulo: Intercom - Sociedade Brasileira de Estudos da Comunicação, 2011. Disponível em:< ntercom.org.br/papers/regionais/nordeste2011/resumos/r28-0697-1.pdf $>$. Acesso em: 03 abr. 2017.

OLIVEIRA, M. R. F. de; PASCHOAL, J. D. A infância e a sociedade do consumo: indústria cultural e imaginário infantil. Imagens da Educação, Maringá, v. 5, n. 1, p. 05-15, 2015. Disponível em: < http://periodicos.uem.br/ojs/index.php/ImagensEduc/article/view/23531>. Acesso em 27 jul. 2017.

OLMOS, A. et al. Criança e Consumo 10 anos de Transformação. São Paulo: Alana, 2016.

PAPALIA, D. E.; OLDS, S. W.; FELDMAN, R. D. Desenvolvimento Humano. 8 ed. Porto Alegre: Artmed, 2006.

PRESTES, L. M.; FELIPE, J. Entre smartphones e tablets: pedofilia, pedofilização e erotização infantil na internet. Pesquisa em foco, São Luís, v. 20, n. 2, p. 4-20, 2015. Disponível em: <http://ppg.revistas.uema.br/index.php/PESQUISA_EM_FOCO/article/view/1009>. Acesso em: 26 abr. 2017.

PONTES, A. A constituição da infância na sociedade midiática: notas para compreensão de outro universo infantil. Rev. Estud. Comun., Curitiba, v. 8, n. 17, p. 213-218, set./dez. 2007. Disponível em:< https://periodicos.pucpr.br/index.php/estudosdecomunicacao/article/view/ 14549>. Acesso em: 18 ago. 2017.

SANTOS, A. M. dos; GROSSI, P. K. Infância Comprada: hábitos de consumo na sociedade contemporânea. Revista Textos \& Contextos, Porto Alegre, v. 6, n. 2, p. 443-454. jul./dez. 2007.Disponível em:< http://repositorio.pucrs.br/dspace/bitstream/10923/8161/2/Infancia comprada_habitos_de_consumo_na_sociedade_contemporanea.pdf $>$. Acesso em: 03 mar. 2017.

SANTOS, I. M. dos. A cultura do consumo e a erotização na infância. Revista Extraprensa, São Paulo, v. 2, n. 2, p. 1-20, ago. 2010. ISSN 2236-3467. Disponível em:< http://www.revistas.usp.br/extraprensa/article/view/74369>. Acesso em: 21 abr. 2017. 
SCHUCHOVSKI, L. N.; PONCIO, A. G. R.; SANTOS, A. F. P. R. dos. O lugar da infância na sociedade de consumo: uma sociologia da relação entre publicidade e infância no Brasil. PANÓPTICA - Direito, Sociedade e Cultura, Vitória, v. 7, n. 1, p. 71-103, jul. 2012. Disponível em:< http://www.panoptica.org/seer/index.php/op/article/view/149>. Acesso em 15 mai. 2017.

SHAFFER, D. R.; KIPP, K. Psicologia do Desenvolvimento Humano: Infância e Adolescência. $8^{\mathrm{a}}$ ed. São Paulo: Cengage Learning, 2012.

SILVA, D. R. da; FESTA, P. S. V. Infância, consumo e ambiente escolar: reflexões sobre o desenvolvimento infantil na sociedade contemporânea. Memorial TCC Caderno da Graduação, v. $1, \quad$ n. $\quad 1$, p. 505-520, 2016. Disponível em:< https://memorialtcccadernograduacao.fae.edu/cadernotcc/article/view/32>. Acesso em: 20 jun. 2017.

SILVEIRA NETTO, C. F.; BREI, V. A.; FLORES-PEREIRA, M. T. O fim da infância? As ações de marketing e a "adultização" do consumidor infantil. Revista Adm. Mackenzie, São Paulo, v. 11, n. 5, p. 129-150, 2010. Disponível em: < $<$ http://www.scielo.br/scielo.php?script=sci_arttext\&pid=S167869712010000500007\&lng=en \&nrm=iso>. Acesso em: 05 jun. 2017.

VALE, C. de S.; MACIEL, T. M. B. F. A configuração etária do sujeito à luz do mercado de consumo. Revista Café com Sociologia, Maceió, v. 5, n. 2, p. 210-223, 2016. Disponível em: http://www.revistacafecomsociologia.com/revista/index.php/revista/article/view/671>. Acesso em 23 ago. 2017.

VELOSO, A. R. Estratégias de segmentação e posicionamento direcionadas para o mercado infantil. 2008. Tese de Doutorado. Universidade de São Paulo, São Paulo. Disponível em: $<\quad$ http://www.teses.usp.br/teses/disponiveis/12/12139/tde-06102008-125154/en.php>. Acesso em 15 ago. 2017.

ZANIRATO, S. H.; ROTONDARO, T. Consumo, um dos dilemas da sustentabilidade. Estudos Avançados, São Paulo, p.1-26, v. 30, n. 88, p. 77-92, 2016. Disponível em: $<$ http://www.scielo.br/scielo.php?pid=S010340142016000300077\&script=sci_arttext $>$. Acesso em: 09 jun. 2017. 